\title{
Celebrating the 40th anniversary of the Italian Mental Health reform
}

\author{
F. Amaddeo ${ }^{\text {* }}$ and C. Barbui ${ }^{2}$ \\ ${ }^{1}$ Department of Neurosciences, Biomedicine and Movement Sciences, University of Verona, Italy \\ 2 Section of Psychiatry, University of Verona, Italy
}

Received 7 November 2017; Accepted 7 February 2018; First published online 13 March 2018

Keywords: Health service research, history of psychiatry, mental health, psychiatric services.

It is again time for celebration, 40 years apart from 1978 when the history of Italian psychiatry has definitely changed moving from a hospital-based system of mental healthcare to a community-based one. After 40 years of implementation, Law 180 is still unique in the international scenario, considering that Italy remains the only country in the world where traditional mental hospitals are outside the law.

As every celebration worthy of respect, we argue that two dimensions need to be analysed: one temporal (what happened in the past? Where are we now? What is our forecast for the future?) and one geographical (how we perceive the reform from inside and how the reform is perceived from outside). If we are able to do that, we may use the resulting knowledge and experience to better manage all the challenges that still lie ahead, in Italy and abroad.

Five years ago, together with Michele Tansella, we wrote a paper (Amaddeo et al. 2012) to celebrate the 35th anniversary of Law 180. At that time we identified some documentable positive effects of the reform that continue to be true today. Community-based mental health services (CMHSs) are well developed throughout the Country, and there are high levels of continuity of care and coordination with other health and social services (Gutiérrez-Colosía et al. 2017). Length of stay in acute psychiatric units is quite low and seems to be correlated with severity of symptoms (Donisi $e t$ al. 2016). Patient and relatives satisfaction with care is higher for outpatient and day-care services and lower for inpatients facilities. Moreover, mortality among patients under the care of Italian CMHSs has been generally lower than that reported by countries with

\footnotetext{
* Address for correspondence: Department of Neurosciences, Biomedicine and Movement Sciences, Section of Psychiatry, Policlinico “G.B. Rossi”, P.le L.A. Scuro 10, 37134 Verona, Italy.

(Email: francesco.amaddeo@univr.it)
}

a hospital-based system of mental healthcare (Grigoletti et al. 2009; Perini et al. 2014).

There are however reasons for concerns. First, although community residential facilities have been developed in the public sector, the scarcity of beds has induced, in some regions, the development of private inpatient facilities (Neri et al. 2011). The second reason for concern is that there is still too much heterogeneity in the availability of resources for mental health throughout the country. This high heterogeneity was recently highlighted by the Italian Society of Psychiatric Epidemiology (SIEP), who carried out an assessment and re-analysis of data collected by the Italian Informative System for Mental Health (SISM) (freely downloadable from http://www.siep.it). In regions and areas where only a few mental health resources are available, the burden of mental disorders has been inevitably and almost entirely sustained by the patients' families, inducing, apart from negative consequences for patients, a negative attitude towards the law in the media, and in some cases, public actions towards its radical revision. Another problem is the difficulty of Italian CMHSs to developing and/or implementing innovative ways of treatment. In most cases, the organisation of services has hardly changed over the last 40 years. This ignores that the Italian society has been profoundly changed and the needs of the elderly and the adolescents, as well as those of new patient populations such as migrants resettled in high-income countries, have not been taken into account in service development (Nosé et al. 2017). Additionally, very few evidence-based specific interventions, such as early intervention teams for young patients with early psychosis have been implemented (Lasalvia et al. 2017).

In this issue of the Journal, the two dimensions cited above (temporal and geographical) are examined by two Editorials, one written by Fioritti (2018) and the other by Becker \& Fangerau (2018), and a Special 
Article written by Mezzina (2018). The Editorials analysed how mental healthcare has developed in Italy during the years before and after Law 180, how the Italian reform informed other policies and reforms; and how experts who live abroad, with a solid knowledge of the Italian situation, see the Italian mental healthcare system. The Special Article gives a view of the main achievements and challenges of the Italian mental health reform law and points out how the Legislation of 1978 was based on the discovery of rights as a key tool in mental healthcare. Roberto Mezzina explains how the rights-based approach should be a beacon that still drives our choices.

Angelo Fioritti started his historical overview from the Fascist regime period when Italian psychiatry underwent a dramatic deterioration of living conditions in psychiatric hospitals, due to international isolation, drive towards control of deviant behaviours, human right violations and even political use of admissions. Fioritti describes in detail the long pathway that determined the approval of Law 180 by means of the decisive action of Franco Basaglia and his collaborators in Gorizia and Trieste. He also analysed how the system of care has changed in the last 40 years, highlighting the key role of two important political decisions: in 1999, the devolution of power for planning, managing and evaluating health services from national to regional level and, in 2008, the progressive closure of forensic psychiatric hospitals, a process that was concluded in April 2017. Fioritti also included a thoughtful description of the potential implications of the Italian reform for the mental health systems of other countries.

Thomas Becker and Heiner Fangerau describe how the Italian system of mental healthcare is perceived abroad. Their reasoning is well-connected with the most recent international scientific literature (papers and books) that analysed the Italian system over the latest 40 years. The authors additionally described the key role of Franco Basaglia. Basaglia and his fellow activists criticised and transformed mental healthcare in Gorizia, Parma, Trieste, Arezzo, Perugia and elsewhere. They formulated a radical, anti-institutional position and joined forces with other reformist movements, e.g. those for workers' and women's rights. These changes have been possible, as Thomas Becker and Heiner Fangerau explained in their editorial because the reformists found a 'window of opportunity' in a specific country and in a very specific historical context.

Law 180 was able to demonstrate that the role of psychiatry may shift from custody and coercion to treatment and care. We hope that these two editorials and the special article, and the anniversary that we celebrate, may stimulate further discussion on how treatment and care should be re-organised in future years in order to maximise their beneficial impact on patient outcomes.

\section{Acknowledgement}

None.

\section{Financial support}

None.

\section{Conflict of interest}

None.

\section{References}

Amaddeo F, Barbui C, Tansella M (2012). State of psychiatry in Italy 35 years after psychiatric reform. A critical appraisal of national and local data. International Review of Psychiatry 24, 314-320.

Becker T, Fangerau H (2018). 40th birthday of the Italian Mental Health Law 180 - perception and reputation abroad, and a personal suggestion. Epidemiology and Social Psychiatry, in press.

Donisi V, Tedeschi F, Salazzari D, Amaddeo F (2016). Preand post-discharge factors influencing early readmission to acute psychiatric wards: implications for quality-of-care indicators in psychiatry. General Hospital Psychiatry 39, 53-58.

Fioritti A (2018). Is freedom (still) therapy? Celebrating the 40th anniversary of the Italian mental health care reform. Epidemiology and Social Psychiatry, in press.

Grigoletti L, Perini G, Rossi A, Biggeri A, Barbui C, Tansella M, Amaddeo F (2009). Mortality and cause of death among psychiatric patients. A twenty year case-register study in an area with a community-based system of care. Psychological Medicine 39, 1875-1884.

Gutiérrez-Colosía MR, Salvador-Carulla L, Salinas-Pérez JA, García-Alonso CR, Cid J, Salazzari D, Montagni I, Tedeschi F, Cetrano G, Chevreul K, Kalseth J, Hagmair G, Straßmayr C, Park AL, Sfectu R, Ala-Nikkola T, González-Caballero JL, Rabbi L, Kalseth B, Amaddeo F, and the REFINEMENT Group (2017). Standard comparison of local mental health care systems in eight European countries. Epidemiology and Social Psychiatry, in press.

Lasalvia A, Bonetto C, Lenzi J, Rucci P, Iozzino L, Cellini M, Comacchio C, Cristofalo D, D'Agostino A, de Girolamo G, De Santi K, Ghigi D, Leuci E, Miceli M, Meneghelli A, Pileggi F, Scarone S, Santonastaso P, Torresani S, Tosato S, Veronese A, Fioritti A, Ruggeri M; GET UP Group (2017). Predictors and moderators of treatment outcome in patients receiving multi-element psychosocial intervention for early psychosis: results from the GET UP pragmatic cluster randomised controlled trial. British Journal of Psychiatry 210, 342-349. 
Mezzina R (2018). 40 years of the Law 180. The aspirations of a great reform, its successes and continuing need.

Epidemiology and Social Psychiatry, in press.

Neri G, Guzzetta F, Pazzi L, Bignami R, Picardi A, de Girolamo G. (2011). How does the residential care system change? A longitudinal survey in a large region of Italy. Community Mental Health Journal 47, 201-208.

Nosè M, Turrini G, Imoli M, Ballette F, Ostuzzi G, Cucchi F, Padoan C, Ruggeri M, Barbui C (2017). Prevalence and correlates of psychological distress and psychiatric disorders in asylum seekers and refugees resettled in an Italian catchment area. Journal of Immigrants and Minority Health, in press.

Perini G, Grigoletti L, Hanife B, Biggeri A, Tansella M, Amaddeo F (2014). Cancer mortality among psychiatric patients treated in a community-based system of care: a 25year case register study. Social Psychiatry and Psychiatric Epidemiology 49, 693-701. 